\title{
RELATOS DE UMA EXPERIÊNCIA MULTICAMPI SOBRE ENSINO DE ESPANHOL A DISTÂNCIA UTILIZANDO TECNOLOGIAS DE INFORMAÇÃO E COMUNICAÇÃO
}

\author{
Chris Royes Schardosim ${ }^{1}$ \\ Lucyene Lopes da Silva Todesco Nunes ${ }^{2}$
}

INTRODUÇÃO

A cidade de Ibirama localiza-se na região do Alto Vale de Santa Catarina (SC). É uma região de colonização alemã (WIESE, 2007), onde não há tradição de ensino do espanhol e nem oferta. A criação do NUBE (Núcleo Universal de Brasileños Españolizados) foi mais uma opção de idioma estrangeiro para a região.

O NUBE é um Núcleo composto por projetos de pesquisa e de extensão com o propósito de desenvolver materiais para um curso básico de espanhol a distância, fazendo uso das Tecnologias de Informação e Comunicação (TIC's) para estudantes dos anos finais do ensino fundamental.

Neste sentido o curso contribui com a educação e a formação dos estudantes e professores envolvidos. Para Moran, Masetto e Behrens (2006), educar é colaborar para a transformação das vidas dos docentes e discentes através de um processo permanente de aprendizagem.

O objetivo deste texto é relatar a experiência no contexto do ensino da língua espanhola com uso das TIC's que ocorre desde 2014, através da parceria de professoras de dois campi do Instituto Federal Catarinense (IFC), descrevendo os resultados da instrumentalização para comunidade com mais um idioma, fundamental para o desenvolvimento profissional.

\section{METODOLOGIA}

\footnotetext{
1 Instituto Federal Catarinense, Professora EBTT, Doutora em Linguística, chris.royes@ibirama.ifc.edu.br

2 Instituto Federal Catarinense, Professora EBTT, Doutoranda em Engenharia e Gestão do Conhecimento, lucyene@ifc-sombrio.edu.br
} 
A metodologia deste relato é de natureza qualitativa (MINAYO, 1998), com abordagem interpretacionista, descrevendo as ações desenvolvidas ao longo de dois anos nos projetos de pesquisa e extensão do NUBE, com a colaboração entre as professoras pesquisadoras Chris Schardosim e Lucyene Nunes, dos campi Ibirama e Sombrio do IFC.

Esse Núcleo é formado, atualmente, por uma equipe de oito colaboradores, sendo três professoras, um técnico em tecnologia da informação $(\mathrm{TI})$, três bolsistas e uma voluntária. Ambas as frentes do NUBE partem de formação teórica dos envolvidos através de levantamento bibliográfico (GIL, 2002) para a preparação dos bolsistas como Design Instrucional (DI) e/ou Tutor (FILATRO, 2008). Entendemos a definição do design instrucional como:

[...] a ação intencional e sistemática de ensino que envolve o planejamento, o desenvolvimento e a aplicação de métodos, técnicas, atividades, materiais, eventos e produtos educacionais em situações didáticas específicas, a fim de promover, a partir dos princípios de aprendizagem e instrução conhecidos, a aprendizagem humana. Em outras palavras, definimos design instrucional como o processo (conjunto de atividades) de identificar um problema (uma necessidade) de aprendizagem e desenhar, implementar e avaliar uma solução para esse problema. (FILATRO, 2008, p. 3).

Uma das etapas do NUBE envolve a criação, no projeto de pesquisa, de um curso que será oferecido na modalidade extensão para estudantes de anos finais do ensino fundamental na cidade de Ibirama. Em 2015 o curso de extensão realizado ocorreu totalmente a distância, através do ambiente virtual na plataforma de software livre Moodle, com o servidor no IFC. A sigla vem do acrônimo de Modular Object Oriented Distance LEarning - MOODLE e é um sistema modular de ensino a distância orientado a objetos. Moodle é um Sistema de Gerenciamento de Aprendizagem em trabalho colaborativo (SGA), um programa criado para facilitar a implementação de cursos na modalidade ensino a distância (NAKAMURA, 2009).

Para o atendimento da parte assíncrona do curso foi utilizada a formação mediada pelas TIC's. Por isso, o curso foi organizado em oito unidades, uma para cada semana, com atividades elaboradas a partir do plugging Hot Potatoes, disponível gratuitamente. As atividades no Hot Potatoes foram editadas manualmente e adaptadas para que estejam simplificadas para 
que os participantes entendam claramente o que deve ser feito. As atividades estão em espanhol e devem ser realizadas em até cinco minutos. Todas apresentam a solução ao final, para que o participante possa conferir as respostas sozinho e refazê-las, se for o caso.

Entendemos que o uso dessas novas tecnologias, como o Hot Potatoes dentro do Moodle, é uma aplicação positiva, resultante do uso das tecnologias na educação. Kenski (2010, p. 34) contribui que esses usos:

[...] refletem-se sobre as tradicionais formas de pensar e fazer educação. Abrir-se para novas educações, resultantes de mudanças estruturais nas formas de ensinar e aprender possibilitadas pela atualidade tecnológica é o desafio a ser assumido por toda a sociedade.

No curso de 2015 tivemos sete inscritos e pretendemos alcançar mais pessoas em 2016, cuja segunda edição do curso está na etapa de planejamento. Para 2016 a metodologia foi modificada, com o curso passando a ser semipresencial, com encontros quinzenais. Dessa forma, esperamos mais participantes, já que cursos a distância são novidade na região e os estudantes nunca tiveram contato com a plataforma Moodle.

Enfatizamos que todo o NUBE é orientado pela base teórica da educomunicação (SOARES, 2011), com interconexão entre diferentes saberes. Acreditamos no uso da tecnologia em meios educativos, utilizando formas de promover a educação e ao mesmo tempo construindo espaços de cidadania, pelos recursos da comunicação e da informação. Desta forma, no curso propiciamos o desenvolvimento das habilidades de escrita, de leitura e de vocabulário básico em espanhol.

\section{RESULTADOS E DISCUSSÃO}

As TIC's, aplicadas aqui como proposta de inserção do curso no ambiente escolar se deparam com uma realidade longe da necessidade ideal ou, quem sabe, utópica. Envolve pensar no uso adequado do ambiente virtual e na decisão por fazer o curso, pois as tecnologias ao se estenderam a todos os âmbitos modificariam as percepções do que é sociocultural e sobre o político-econômico (ALONSO, 2008). 
A elaboração do material parte da perspectiva da educomunicação, com a construção de novas práticas pedagógicas, com maior interconexão entre áreas, docentes e projetos didáticos (SOARES, 2011, p. 83). A elaboração do curso foi pensada com a intenção de disponibilizar a aprendizagem dos conteúdos de maneira interativa e comunicativa, isto é, permeado por uma prática pedagógica dialógica (FREIRE, 1996), buscando a articulação teórico-prática.

Durante todo o desenvolvimento do projeto há a articulação entre o ensino, a pesquisa e a extensão, já que se trata de um curso para o ensino da língua espanhola para a comunidade e os bolsistas são formados enquanto DI e tutores, pesquisando sobre educação a distância e ensino de línguas.

A participação da comunidade é fundamental: a acolhida nas escolas para divulgação do curso foi bastante positiva. Porém, das 20 vagas oferecidas, sete foram preenchidas. $O$ fato de existir um projeto com esses princípios comunicativos e tecnológicos que envolve estudantes do ensino médio integrado possibilita o fortalecimento da formação destes discentes, bem como o aprimoramento das bases desta modalidade de ensino.

Portanto, este projeto engloba a formação em pesquisa dos estudantes do ensino médio técnico integrado, o contato com a comunidade, a interconexão entre diferentes áreas do conhecimento, o ensino de língua espanhola e a utilização de tecnologias de educação a distância.

Para os participantes ibiramenses está sendo uma inovação e uma grande oportunidade de novos conhecimentos, pois é nítida a falta de acesso a um curso de idiomas e a dificuldade financeira, bem como a disponibilidade de tempo para se deslocar a um curso presencial.

Por isso, o curso virtual NUBE foi uma oferta útil, acessível e gratuita para a comunidade. Em 2016 será dada continuação à utilização das ferramentas da educação a distância, bem como à formação de Dls, tutores e educomunicadores. Esses novos atores sociais são de grande importância para a educação na atualidade, já que os jovens estão distantes dos parâmetros escolares por vivenciarem uma cultura tecnológica, marcada pela comunicação em tempo real.

\section{CONSIDERAÇÕES FINAIS}


O NUBE surgiu pela carência de ensino de espanhol na região de Ibirama, Alto Vale, Santa Catarina. Por isso a ideia de oferecer um curso de espanhol a distância para estudantes da região, de forma a propiciar o contato com o idioma. O NUBE atingiu seus objetivos ao desenvolver, divulgar e disponibilizar o curso de espanhol a distância na cidade de Ibirama e região, através da plataforma Moodle.

Contudo, a limitação por nós enfrentada foi a baixa procura pelo curso. Creditamos isso ao ineditismo do curso e ao uso das TIC's, ainda desconhecidas por muitos estudantes. Por isso alteramos a metodologia para o próximo curso NUBE, com encontros presenciais.

Ainda assim, o mais importante no decorrer dessa experiência aqui relatada foi a oportunidade de poder mostrar que a tecnologia consegue superar suas metas e ser tão eficaz quanto as outras modalidades de ensino quando utilizada da maneira em que o beneficiado é a sociedade e não somente um indivíduo.

\section{REFERÊNCIAS}

ALONSO, K. M. Tecnologias da informação e comunicação e formação de professores: sobre rede e escolas. Educ. Soc., Campinas, v. 29, n. 104, p. 747-768, out. 2008.

FILATRO, A. Design instrucional na prática. São Paulo, SP: Pearson Education do Brasil, 2008.

FREIRE, P. Pedagogia da autonomia: saberes necessários à prática educativa. São Paulo: Paz e Terra, 1996.

GIL, A.C. Métodos e técnicas de pesquisa social. São Paulo: Atlas, 1999.

KENSKI, V. M. Educação e tecnologias: o novo ritmo da informação. 7. ed. Campinas, SP: Papirus, 2010.

MANCE, E. A. A Revolução das Redes. Petrópolis, Ed. Vozes, 2000 
MINAYO, M. C. S. Pesquisa Social: teoria, método e criatividade. 9. ed. Petrópolis: Vozes, 1998.

MORAN, J.M.; MASETTO, M.; BEHRENS, M. Novas Tecnologias e Mediação Pedagógica. 12. ed. Campinas: Papirus, 2006.

NAKAMURA, R. Como criar um curso usando a plataforma de Ensino a Distância: MOODLE. São Paulo: Farol do Forte Editora, 2009.

SOARES, I. O. Educomunicação: o conceito, o profissional, a aplicação contribuições para a reforma do ensino médio. São Paulo: Paulinas, 2011.

WIESE, H. Terra da fartura. Ibirama: Edigrave, 2007. 